\title{
Technological and Economic Analysis of Logistic Activities in Interior Parts Manufacturing
}

\author{
Libor Kavka', Iveta Dočkalíková', Zdeněk Čujan', Gabriel Fedorko ${ }^{2 *}$ \\ 1 College of Logistics, Palackého 1381/25, 75002 Přerov, Czech Republic \\ 2 Technical University of Košice, Faculty of Mining, Ecology, Process Control and Geotechnology, Letná 9, 042 \\ 00 Košice, Slovak Republic \\ *Corresponding author's e-mail: gabriel.fedorko@tuke.sk
}

\begin{abstract}
Logistics activities play in important role in supporting the production process for a wide range of products in many industries, such as the automotive or electrical engineering industries. In the automotive industry, they are present throughout the entire production cycle. To perform these activities, various technologies as well as economic aspects must be considered and employed. This contribution describes the technology of interior parts manufacturing for the automotive industry and specifies costs connected to the preparation and setting of machines and devices in individual workplaces as well as the cost items linked with their production and subsequent logistic activities.
\end{abstract}

Keywords: interior parts, manufacturing technology, material flow, push system, pull system, Kanban, logistics activities.

\section{INTRODUCTION}

Logistics activities belong among company activities which are characterized by their continuous nature ensuring an uninterrupted flow of materials and services throughout the entire production process. These activities include, for example, the disposal, recycling or further use of products. They are largely determined by the technologies a company uses in its production process [1]. The company may perform these activities by its own means, or it may outsource them. Outsourcing is a powerful tool for streamlining logistics activities. According to Arif and Jawab [2], outsourcing of logistics activities plays an important role in increasing the efficiency of logistics activities and contributes to the overall performance of logistics services. For the same reasons, companies may also employ computer simulations. More details about the use of a software tool to optimize logistics activities in the field of intralogistics may be found in Poulimenos et al. [3]. Another example of the use of computer simulations to support logistics activities is presented by Straka et al. [4].
One of the computer simulation methods is the Monte Carlo method [5,6]. Currently, logistics activities need to adapt to the challenge of changing material flow requirements in line with the versatile production environments of the future that aim to produce personalized products under the same conditions and with the same performance as today's mass production [7]. Logistics activities must be performed in such a way as to ensure the required quality of the resulting products [8]. The issue of logistics processes quality was studied more thoroughly by Kablashova et al. [9]. In their research, they concluded that establishing a quality management mechanism for logistics activities must be part of the quality management system in the company.

Logistics activities play an important role in various fields of industry [10], including, for example, the wood forest industry [11], mineral extraction industry [12], or automotive industry [13]. In the field of the automotive industry, the issue of logistics activities has been thoroughly studied. Detailed discussion offers, for example, Knoll et al. [14]. For automotive companies, it proves 


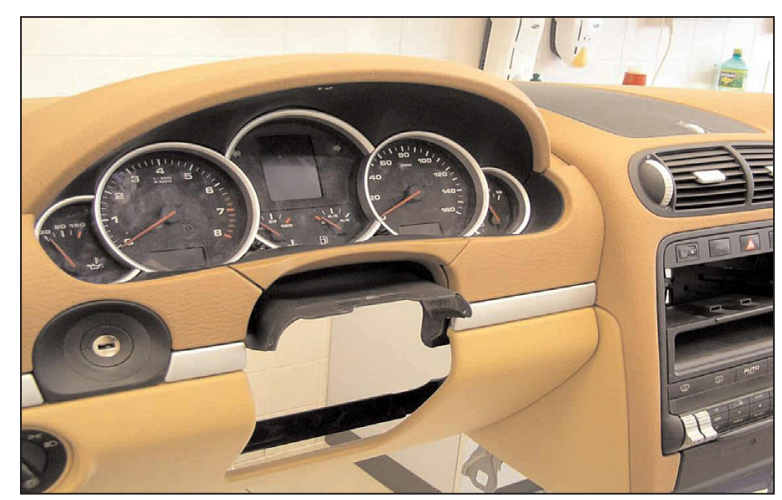

Fig. 1. Selected interior parts of a dashboard

important to pay due attention to logistics activities [15], because they are part of many business areas, such as production logistics. Kampf [16] describes this issue in more detail. The technological and economic analysis of logistics activities may be performed in different ways, but it must always provide relevant information and outputs [17]. This contribution presents a detailed technological and economic analysis of logistics activities applied in the field of the automotive industry. The aim is to point out the potential of its implementation, using the production of dashboard as an example.

\section{INTERIOR PARTS MANUFACTURING}

Most of the interior parts used in the automotive industry, safety parts in particular, are usually made from two main parts (lower supporting part and upper design part) interconnected with polyurethane layer into a non-collapsible sandwich.

The lower supporting part is manufactured by injection moulding technology from PVC granulate with a percentage of added glass fibres. The upper part, which creates the car interior design, is made to meet customer's requirements - from natural or artificial leather in a selected colour.

The non-collapsible sandwich part is manufactured in a robotic workplace, the lower and upper parts are interconnected with a polyurethane filling, which is created by a chemical reaction of the two main constituents - polyol and isocyanate (TDI) and other additives that are not substantial.

\section{MANUFACTURING TECHNOLOGY}

Manufacturing technology of interior parts for automotive is basically the same. With regards to the manufacturing character and its complexity, the dashboard serves as a good group representative for interior parts, which is the most complicated and most time-consuming part of the entire set.

The dashboard belongs to the group called "A" parts, which are safety parts, whose production requires a specific schedule.

Manufacturing procedure:

1) Manufacturing of lower supporting part by injection moulding technology from PVC granulate,

2) Manufacturing of upper part:

- from powder PVC by its melting and acting of centrifugal force on a closed mould (artificial leather with surface design),

- from PVC foil by vacuum moulding as the foundation for natural leather (vacuum space moulded PVC foil serves as the upper part for sandwich manufacturing),

3) Perforation performance for easier airbag release,

4) Frame installation for a safety feature (airbag),

5) Manufacturing of a three-layer non-collapsible sandwich,

6) Final shape milling,

7) Dashboard coating with natural leather (outsourcing),

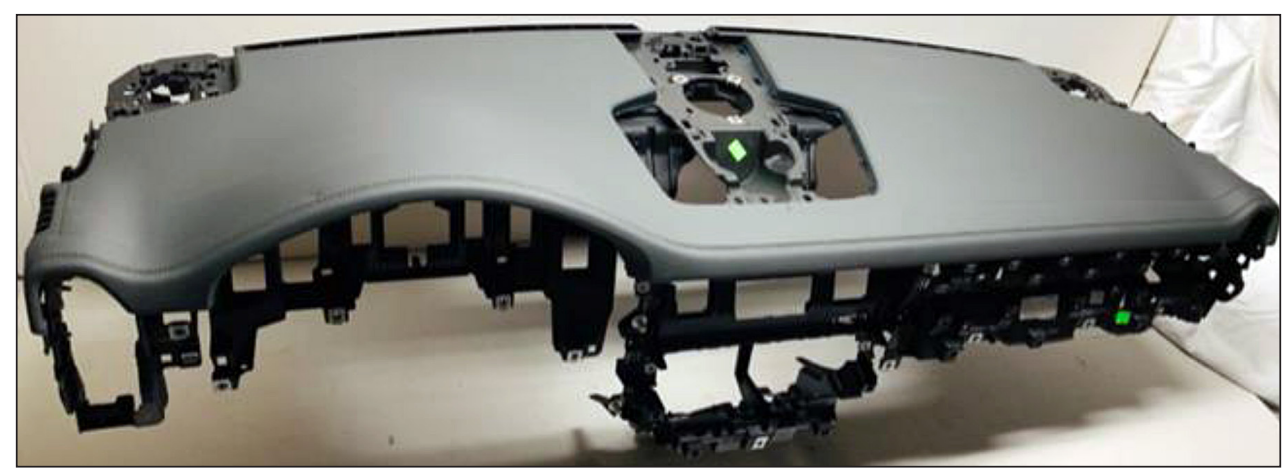

Fig. 2. Semi-finished dashboard 
8) Final assembly, see Figure 2 (clamps installation for wiring, air conditioning installation and other components of a dashboard).

In the course of conducting individual technological operations, they are identified by placing a number code and by a record into the enterprise's management system, which provides a quick and safe traceability.

\section{TECHNOLOGICAL ANALYSIS OF MANUFACTURING PROCESS}

The contents of technological analysis are the description of manufacturing technology of a selected interior part representative, e.g. individual parts of a non-collapsible dashboard.

\section{Manufacturing of lower supporting part}

The lower supporting part is manufactured by injection technology into a one-piece mould from PVC granulate with a percentage of added glass fibres. A common hydraulic injection moulding machine is used, equipped with a clamping board that enables to clamp the injection mould. Batching of the PVC granulate with glass fibres is fully automated including the exemption of the finished product after the mould opening. When tempered, the product is replaced by a manipulator to a manually operated workplace where injection system and overflows are removed. When the part is tagged with a number code, the lower supporting part is transferred for the subsequent operation.

The subsequent technological operation is the installation of a safety feature which is a frame for airbag placement. With the help of a special machine, the frame is automatically screwed to the supporting part with bolted joints that have a set torque magnitude. When the part is inspected and tagged with a number code, the upper part is transferred to the robotic workplace.

\section{Manufacturing of upper design part}

\section{a) from powder PVC}

The manufacturing of the upper part from powder PVC is performed on a special machine in a rotating mould, which has a cavity in the shape of the undevelopable surface of the dashboard's upper part including the design. This cavity in open state is filled with necessary amount of powder PVC and the mould is closed. The cylindrical mould is placed in bearings with two pins where one of them is hollow for gas inlet. When the mould starts to rotate, the gas turns the powder PVC into liquid state. Thanks to the centrifugal force, the mould cavity that creates the dashboard's upper part including the design is filled. After tempering of the inner space of the mould and its stopping, the warm dashboard's upper part with the design surface is removed in gloves, then the overhanging parts are manually cut off, the final product (artificial leather) is tagged with a number label and transferred for the subsequent operation.

The subsequent technological operation is the perforation of artificial leather in the airbag area, which ensures safe and easier functionality. The perforation is performed on a special machine by partial but deep incision of the artificial leather. At the end of the performed perforation the upper part is provided with a hole at its edge, which serves as a check of the performed perforation before robot launching. The part is also tagged with a number code.

\section{b) natural leather using PVC foil}

The manufactured upper part of the dashboard from PVC foil serves only to produce the three-layer non-collapsible sandwich. It is manufactured from PVC foil using the technology of vacuum forming to make the mould which has the shape of the upper dashboard. Foil heating and its perfect forming on the mould is performed with the use of vacuum. When the upper part is formed, the overhanging parts are manually cut off, the final product is tagged with a number label and transferred to the subsequent workplace.

\section{Manufacturing of a three-layer non-collapsible sandwich}

The three-layer non-collapsible dashboard is manufactured on a robotic workplace in a twopart mould. The upper part of the dashboard is inserted into the bottom part of the open mould, the design part towards the bottom of the mould and the lower supporting part of the dashboard is placed into the top part of the open mould. When the robot is switched on, the automated inspection of the previous operation - laser beam perforation through the hole in the upper part of the dashboard - is performed. The robot lays out the main constituents, polyol and isocyanate including additives, through the mixing head and the mould is 


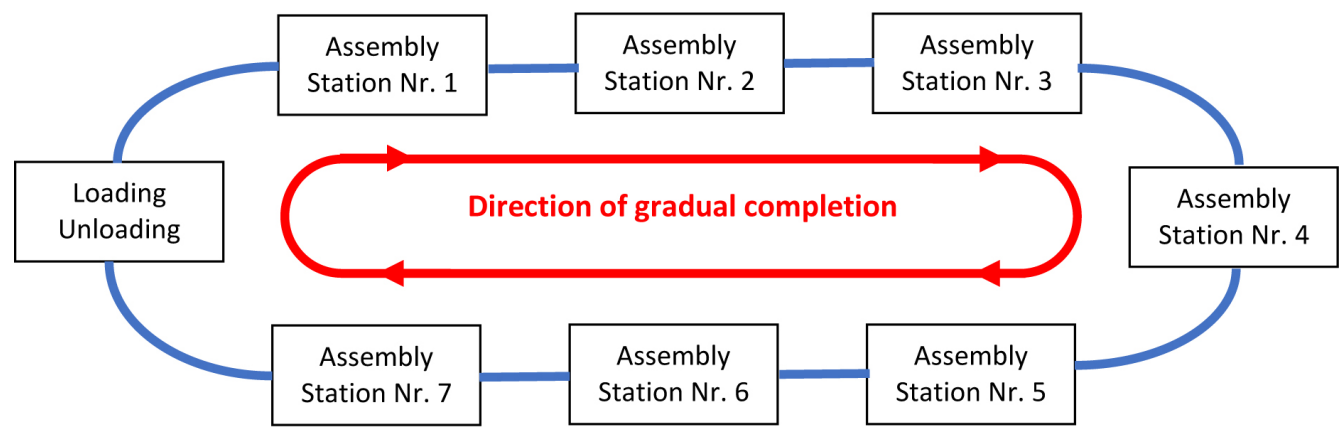

Fig. 3. Assembly line scheme

automatically closed (the top part of the mould is placed on the bottom part of the mould by a rotating movement). Both main constituents chemically react inside the mould and the polyurethane mixture which interconnects the upper and lower part of the dashboard is created the three-layer non-collapsible sandwich is made.

The subsequent technological operation is the edge milling to achieve the final required shape according to the drawing documentation. It is performed on an automated milling machine with a shank milling cutter $\phi 1.6 \mathrm{~mm}$ in diameter.

The upper part of the dashboard made of PVC foil is used in a similar way. After the technological operation of milling, this part is supplied within outsourcing to be coated with natural leather.

\section{Final assembly of the dashboard}

The final assembly of the dashboard is done on an assembly line with a free work cycle time.
The clamps for wiring are attached on the line, the air-conditioning is installed including other equipment that constitute the dashboard.

Material movement between individual workplaces is performed on special one-way carriers, which from practical point of view enables to use a belt (or any other) conveyor including the application of automated control features and visa versa utilization of simple manually operated lift trucks.

\section{ECONOMIC ANALYSIS OF MANUFACTURING PROCESS}

Economic analysis specifies cost items that enter the manufacturing process $[18,19]$. The objective of every logistic activity is the aim to reduce costs or increase productivity [20]. These stated objectives can be achieved by individual components of logistic performance that influences logistic services and logistic costs [21].

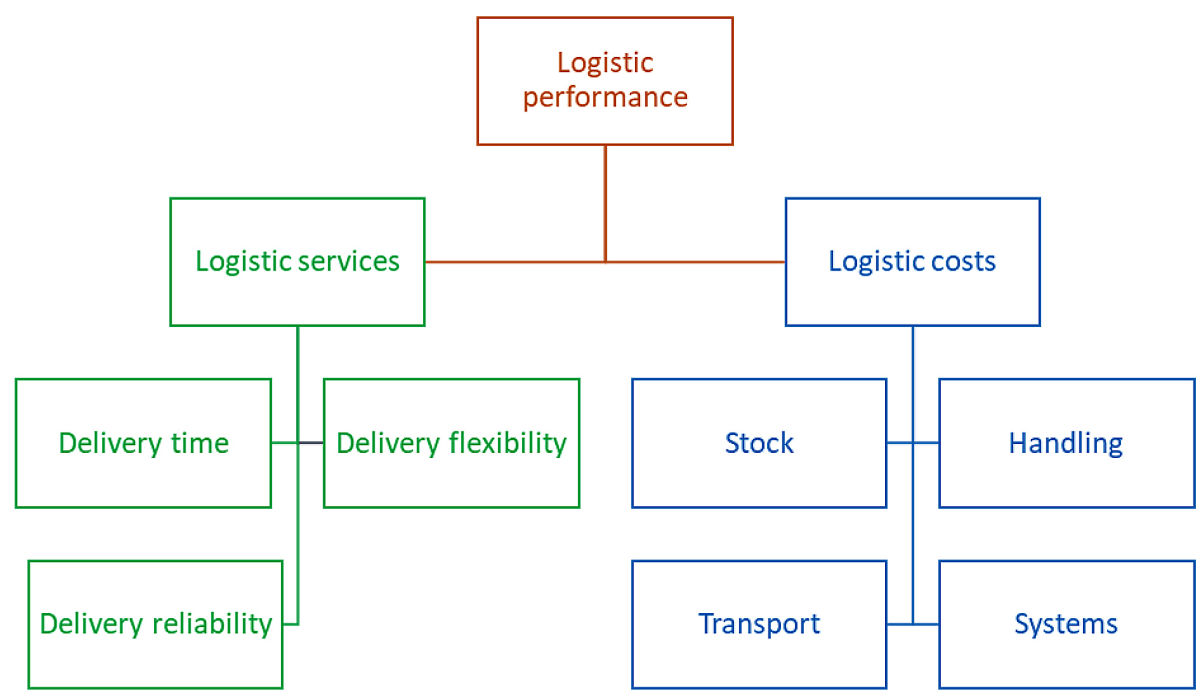

Fig. 4. Logistic performance components 
As far as logistic services are concerned, the client is usually aware of only the following performance components:

- delivery time - it defines the time that is necessary from the customer's order placement till the moment of physical delivery of the goods to the customer. Shorter lead times enable the customers to keep lower stock.

- delivery reliability - it defines the delivery probability of ordered goods in predetermined delivery time.

- delivery flexibility - it defines the ability of the logistic system to respond to customer's requirements change immediately.

Logistic costs include the following items:

- stock and storage costs - they arise because financial resources are bound to inventory (insurance, shrinkage, damage) and there are costs spent to keep warehouse positions, stock removal and storage operations.

- system costs - they include planning costs, flow material checking and manufacturing management costs.

- transport costs - these are spent on intra-company and external transport. It is necessary to distinguish emergency costs component (e.g. forklifts) and dependent component (e.g. energy consumption of transport equipment).

- handling costs - they include all costs for packaging, handling operations and commission work. We distinguish emergency costs component and handling costs component which is dependent on the volume (e.g. wrapping material, preservatives, labels).

- overhead costs - overhead costs are those that cannot be accurately assigned to a specific performance. These costs are common for more manufacturing operations. Common costs are often described as central overhead costs and to improve economic calculations that include optimization, precise calculation and manufacturing processes management it is necessary to analyse these costs in detail.

The frame contract signed between the final purchaser and the interior parts supplier guaranteed the delivery of 45000 sets/year, which makes 200 sets/shift after recalculation. The stated amount is the average required amount. The real amount of sets was given by daily release order, which ranged in a variation of 10 pieces of sets in the average required amount.
The manufacturing machines and devices are a property of the supplier, the moulds for injection technology and reinforcement are in the property of the final customer. Raw materials and semi-finished products necessary to produce interior parts were supplied by companies that had been selected by the final customer's central purchasing department.

The raw material supply and semi-finished products were ordered with the interior parts manufacturer/supplier in optimal amount and piece numbers as well as kept in the warehouse with necessary reserve stock.

\section{Time study}

To conduct the time study, we have to know the process, operation and workplace first. We draw the workplace layout and observe the sequence of job performance, or as the case may be, shoot a video. As soon as we recognise individual repetitive jobs, we record them, we create abbreviations for them and we measure the total time of these jobs with a stopwatch several times. We identify jobs that do not add value, we process the measured data and analyse the results [22].

The benefit of the time study is easy identification of wasting in individual operations. The time study enables the arrangement of job motions in optimal sequence, description of standard job procedures and determination of added value of operation being performed [22].

It is used with regularly repetitive operations when we only check the sequence of job performance on a pre-prepared form. It serves for the determination of duration time of a working operation. It provides information for working procedure analysis $[23,24,25,26]$.

Procedures for a time study performance:

- prepare a spreadsheet for the analysis,

- learn the production process and workplace,

- draw a layout,

- identify working motions,

- measure the whole cycle,

- measure working motions,

- define irregular jobs,

- specify movements that do not add value,

- process the results, do the final analysis [22].

The time study was conducted for all technological operations related to dashboard manufacturing as the group representative of interior parts in the extent of five measurements by ten 
Table 1. Time study

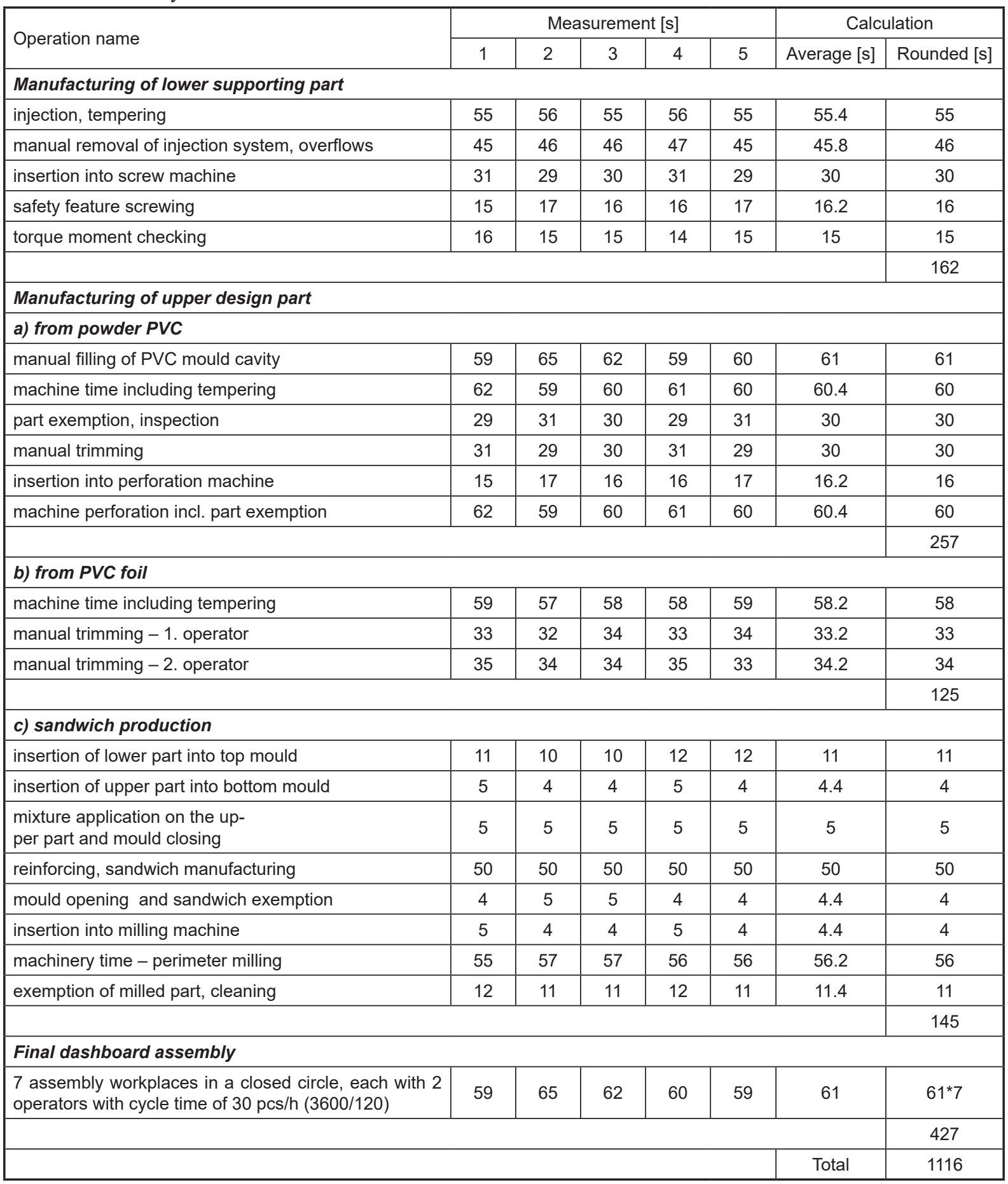

pieces. For the measurements of 10 pieces the arithmetic average was calculated and rounded to the whole number.

\section{Value stream mapping (VSM)}

The current state mapping has been extended with rectangles for individual manufacturing operations and information about jobs during the basic manufacturing operations.
It is information about:

- $\mathrm{C} / \mathrm{T}$ - Cycle time,

- $\mathrm{C} / \mathrm{O}$ - Time for operation preparation,

- number of shifts,

- inserted batch into production.

The analysis of the value stream provided information about time reserve when manufacturing the lower supporting part by injection technology. The injection machine has a relatively high capacity which enables manufacturing of lower supporting 


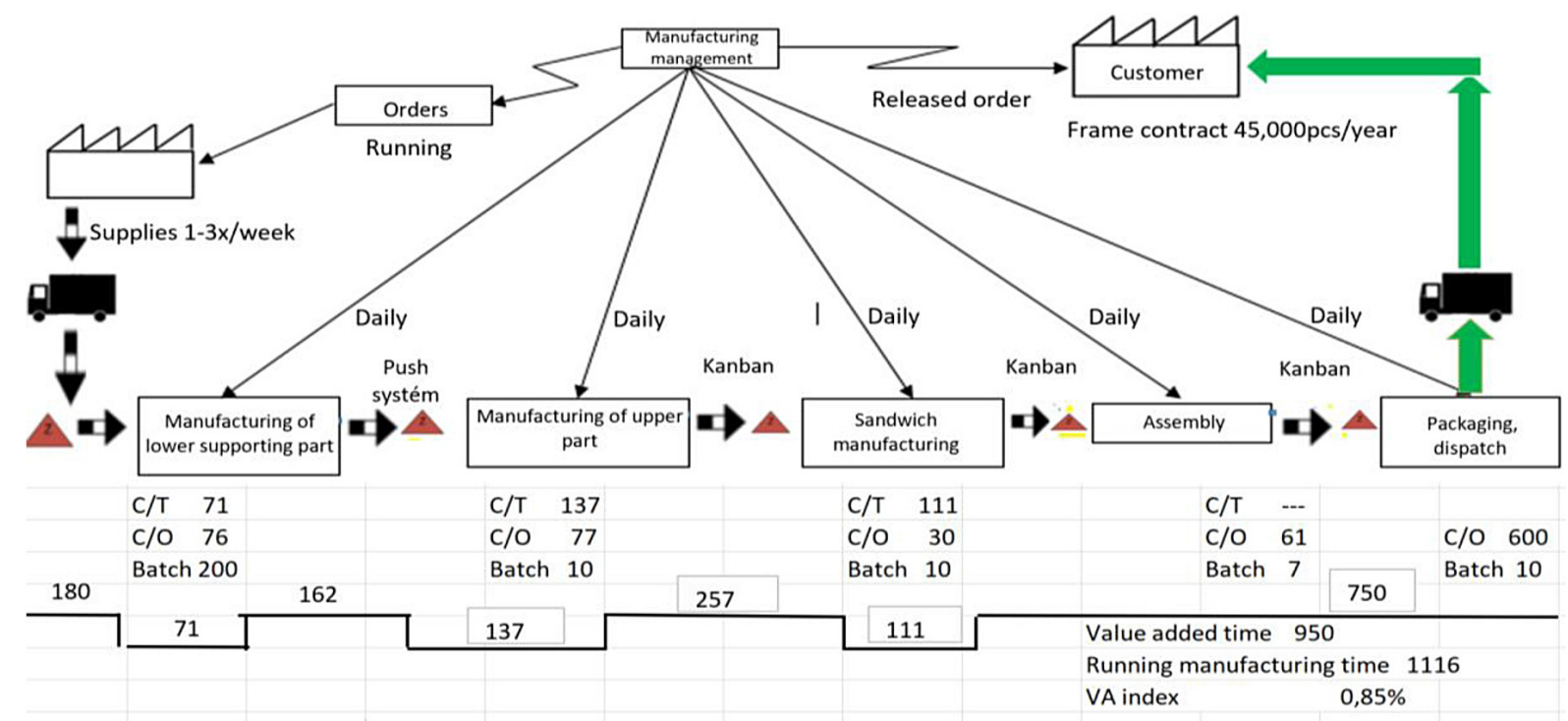

Fig. 5. Value stream mapping

parts in two shifts to cover weekly consumption. The manufacturing system in this area is a pull system.

The other technologies make use of kanban board with manufacturing management in small production batches.

Individual technologies take place continuously and there is no unwanted material piling, resp. there is no constraint occurrence.

\section{Elementary data}

The following fundamental input data were used in the economic analysis:
- effective shift work time - 26100 s,

- number of shifts per day - 1 shift,

- effective daily work time - $26100 \mathrm{~s}$,

- customer's requirement - 45000 pcs·year ${ }^{-1}$,

- number of workingdays in a month - 21 days,

- customer's daily requirement - $\cong 195 \mathrm{pcs} \cdot$ day $^{-1}$,

- takt time - $\cong 120 \mathrm{~s}$.

The customer requires the company is able to produce minimally one product every 120 seconds, i.e. one product in every 2 mins, i.e. $218 \mathrm{pcs} \cdot \mathrm{shift}^{-1}$.

Stock in days $=\frac{\text { stock in warehouse }}{\text { takt time }}$

Table 2. Costs and revenue

\begin{tabular}{|c|c|c|c|c|}
\hline \multicolumn{5}{|c|}{ Costs } \\
\hline \multicolumn{2}{|r|}{ Items } & Costs $€ / p c$ & Costs per month & Amount pc/month \\
\hline \multirow[t]{4}{*}{ Material } & PVC granulate & 3.8 & 15960 & \multirow{10}{*}{4200} \\
\hline & PVC foil & 11.34 & 47628 & \\
\hline & PVC powder & 0.38 & 1596 & \\
\hline & PU foam & 0.16 & 672 & \\
\hline Purchased parts & bolts, clamps, frame, $\mathrm{AC}$ etc. & 210.2 & 882840 & \\
\hline \multirow[t]{2}{*}{ Wages } & 22 operators & 8.162 & 34280.4 & \\
\hline & 10 handlers & 3.746 & 15733.2 & \\
\hline Machines & & 934.90 & 3926580 & \\
\hline \multirow[t]{2}{*}{ Energy } & & 620.30 & 2605260 & \\
\hline & $\Sigma$ & 1790.99 & 7530549.60 & \\
\hline \multicolumn{5}{|c|}{ Incomes } \\
\hline Item & $€ / p c$ & pc/month & $€$ & $€$ \\
\hline Dashboard & $2200,-€ \cdot p_{c s^{-1}}$ & 4200 & & $9240000 € \cdot$ month $^{-1}$ \\
\hline Revenue & & & 1709450.40 & \\
\hline
\end{tabular}


Input material stock:

- PVC granulate - $7602 \mathrm{~kg} ;\left(2.1 € \cdot \mathrm{kg}^{-1}\right)$,

- PVC foil - 4620 m.month-1; $\left(54,-€ \cdot \mathrm{m}^{-1}\right)$,

- PVC powder - $2520 \mathrm{~kg} \cdot$ month $^{-1} ;(1.81 €$. $\mathrm{kg}^{-1}$,

- PU foam $-840 \mathrm{~kg} \cdot \mathrm{month}^{-1} ;\left(1.52 € \cdot \mathrm{kg}^{-1}\right)$.

Unstated purchased semi-finished products and parts necessary for the final dashboard assembly are included in one item see Table 2.

\section{Relevant calculation part}

The input data is as follows:

- time V (Production) - $950 \mathrm{~s}$,

- $\mathrm{VA}$ - index $-0.85 \%$,

- cycle time - $130.5 \mathrm{~s}$,

- inventory turnover - $\cong 12.1$ times,

- turnover time - 29.75 days,

- minimal operators number -8 operators.

The constraint with the longest cycle time is the manufacturing of the upper design board and production of the three-layer non-collapsible sandwich which creates the dashboard. Ability to meet customer's requirements - $122 \mathrm{pcs} / \mathrm{shift}$ $\leq 200 \mathrm{pcs} /$ shift the company is able to meet customer's requirement and supply interior parts in required amount and quality. Using the above input data, an economic analysis was performed, the results of which are presented in Table 2.

\section{CONCLUSION}

This contribution describes the technology of interior parts manufacturing. The dashboard was chosen as their representative, it belongs to the group called "A" parts, which are safety parts whose production requires a specific schedule.

All technological operations related to the safety parts manufacturing must ensure their flawless finish. This requirement can be met by a lean manufacturing system called Poka Yoke. Poka Yoke system helps to prevent inadvertent errors.

Poka Yoke can be understood as a mechanical or electric/electronic manufacturing concept, mechanism or device that avoids the production of a disagreeing/defect product. The device prevents for example a possible components interchange, wrong order of individual technological operations or assembly in the manufacturing process or a faulty assembly of a feature. The concept prevents the operator to continue in product manufacturing or assembling if something is missing or is mounted in the wrong way.

The workplace arrangement creates a closed circle which minimizes needs for material handling. The processes are set in such a way that after machine processing " $\mathrm{j}$ " follows machine processing " $i$ ". This workplace arrangement is suitable for one-piece production, resp. for shortrun or serial production, where it might be used in the case when the technological process requires repetitive machine operations for one-piece or short-run batches.

The economic analysis contains the basic parameters that are related to technological operations and are only indicative. Obviously, the other related calculations are indicative as well.

\section{Acknowledgements}

This work is a part of these projects VEGA 1/0600/20, KEGA 012TUKE-4/2019 and SK-SRB-18-0053.

\section{REFERENCES}

1. Souza Santos P.V. Introduction of technologies in favor of efficiency in logistics: a case study in the service sector. Navus-Revista de Gestao e Tecnologia 3, 2019, 55-68.

2. Arif J. and Jawab F. Outsourcing of logistics' activities: Impact analysis on logistics service performance. In: 2018 International Colloquium on Logistics and Supply Chain Management (Logistiqua) IUM on Logistics and Supply Chain Management (Logistiqua). pp. 88-92, 2018.

3. Poulimenos D., Bechtsis D., Vlachos D. and Iakovu E. A software tool for optimizing intra-logistic activities. In: 28th European Symposium on Computer Aided Process Engineering. pp. 439-444, 2018.

4. Straka M., Malindzakova M., Trebuna P., Rosova A, Pekarcikova M. and Fill M. Application of ExtendSim for improvement of production logistics' efficiency. International Journal of Simulation Modelling. 16, 2017, 422-434.

5. Fabianova J., Kacmary P. and Janekova J. Operative production planning utilising quantitative forecasting and Monte Carlo simulations. Open Engineering 9, 2019, 613-622.

6. Sopkuliak P., Palencar R., Palencar J., Suroviak E. and Markovic J. Evaluation of uncertainties of ITS90 by Monte Carlo method. In: Cybernetics and 
Mathematics Applications in Intelligent Systems, CSOC 2017, vol. 2. pp. 46-56, 2017.

7. Schuhmacher J. and Hummel V. Development of a descriptive model for intralogistics as a foundation for an autonomous control method for intralogistics systems. In: 8th CIRP Sponsored Conference on Learning Factories (CLF 2018) - Advanced Engineering Education \& Training for Manufacturing Innovation. pp. 225-230, 2018.

8. Cempirek V., Drahotsky I., Prusa P. and Nachtigal P. Factors Influencing Warehouse Construction in Relation to Safe Operation. In: CLC 2015: Carpathian Logistics Congress - conference proceedings. pp. 171-177, 2016.

9. Kablashova I.V., Rodionova V.N., Turovets O.G. and Lutsenko M.S. Quality management of logistics processes in the context of methodology of the TQM system. In: VISION 2020: Sustainable Economic Development, Innovation Management, and Global Growth, vols I-IX, 2017. pp. 100-1007, 2017.

10. Romero Postiguillo J., Del Campo Yague J. M., Santamera Sanchez J. A. Evolution, trends and design parameters for the management of areas of logistic activities in Spain. Revista de La Construccion. 16, 2017, 274-283.

11. Fallas-Valverde P., Quesada H. J. and Madrigal-Sanchez J. Implementation of lean thinking principals to logistic activities: a case study in a wood forest industry. Tecnologia en Marcha 31, 2018, 52-65.

12. Mendes F.B., Silva C. C. and Tammela I. Operational analysis of a logistic process in the petroleum exploration and production chain integrating ishikawa, bowersox and liker tools in problem identification: A case study. Sistemas \& Gestao. 13, 2018, 283-294.

13. Kliment J. and Solc M. The process of identification security risks in the automotive industry. In: Informatics, Geoinformatics and Remote Sensing Conference Proceedings, SGEM 2016, vol. I. pp. 475-482, 2016
14. Knoll D., Reinhart G. and Prueglmeier M. Enabling value stream mapping for internal logistics using multidimensional process mining. Expert Systems With Applications. 124, 2019, 130-142.

15. Hlatka M., Bartuska L. and Lizbetin J. Application of the Vogel approximation method to reduce transport-logistics processes. In: 18th International Scientific Conference-LOGI 2017. pp. $1-8,2017$.

16. Kampf R., Hlatka, M. and Bartuska L. Optimization of production logistics. Advances in Science and Technology Research Journal. 12, 2018, 151-156.

17. Tomkova E., Husakova, N. and Strohmandl Possibilities of economic efficiency solution in road haulage. In: Transport Means 2015. pp. 694-697, 2015.

18. Čujan Z. Logistika výrobních technologií. VSLG Přerov o.p.s., Přerov, Czech republic, 2013.

19. Košturiak J. and Frolik Z. Štíhlý a inovativní podnik. Alfa Publishing, Praha, Česká republika, 2006.

20. Rother M., Shook J., Womack J. and Jones D. Learning to See: Value Stream Mapping to Add Value and Eliminate MUDA. Industrial Engineering and Management Press, Lean Enterprise Institute, Inc., 2009.

21. Quarterman L. and Snyder B. Value Stream \& Process Mapping. Productivity Press, Bellingham, USA, 2017.

22. Mašín I. Mapování hodnotového toku ve výrobních procesech. Institut průmyslového inženýrství, Liberec, Czech republic, 2003.

23. https://www.systemonline.cz/rizeni-vyroby/kanban-vyroba-tahem.htm.

24. http://www.leanmanufacturing-japan.com/white paper/value_stream_mapping_of_a_comp.html.

25. https://managementmania.com/cs/value-streammapping.

26. http://modernirizeni.ihned.cz/?p=600000_d\&\&art icle[id] $=13955170$. 